\title{
12 YEARS OF THE NATIONAL QUALITY AWARD OF THE SLOVAK REPUBLIC
}

\author{
MONIKA JURKOVIČOVÁ, KATARÍNA KAŠUBOVÁ
}

\section{INTRODUCTION}

The role of the Slovak Office of Standards, Metrology and Testing as the central state administration organization is to create and to keep reliable quality infrastructure tools. The primary aim of these tools is to set a competitive and effective background in the Slovak Republic and to support the protection of consumers - of each citizen. The tools of quality infrastructure in European measures are standards, metrology and conformity assessment, as well as accreditation and market surveillance to the extent of processes directed at enforcement of directives, mainly a new approach. The Slovak Office of Standards, Metrology and Testing (SOSMT) is the coordinator of state quality policy in the Slovak Republic.

The National Quality Award of the SR is the most prestigious quality award for organizations, the highest accolade to be gained nationally, ultimately enabling the winner to gain national recognition amongst competitors in terms of quality management. The competition assesses management in a particular industry in view of unquestionable evidence of success achieved in implementation of the organization's strategy and permanent improvement of its performance (First Information on the Competition and the Application Form for the National Quality Award of the Slovak Republic 2012, 2011).

The competition for the National Quality Award of the Slovak Republic (hereinafter "competition") refers to the principal activity of the state quality policy that is presented by the National Quality Program of the SR. It is based on exhaustive, objective assessment of the effectiveness and quality of all activities within an organization. By means of self-assessment, it measures the extent to which the organization's results (satisfaction of customers, employees, assets for the society and key performance results) correspond to the enablers created by the organization's top management by means of strategy and planning, human resource management, partnerships, funds, and management and process systems. The correct implementation of these constituents of management results in excellent results of organizations in both the financial and other than financial aspects.

The competition has been organised regularly since 2000 and its individual phases last in total twelve months. The competition is announced every year in November during the European Quality Week in the Slovak Republic and ends 
by announcement of results presented in an award ceremony in November of the next year. The recognition within a particular category of the competition is awarded to a successful organization having demonstrated unique excellence within a specific field or line of business and thus having qualified to serve in view of its overall performance and inspirational conduct to stakeholders as an example for other organizations.

Who may apply for the award? Any successful organization of the public and business sector interested in having their management system activities assessed with focus on results and priorities, driving employees to put efforts in permanent improvement of management system and professional development, assessing the effectiveness and quality of the organization's performance, assessing the achieved level of the total quality management, obtain a material evidence for customers with respect to meeting their needs and expectations and foster the organization's position on both domestic and foreign markets.

The competition is announced annually by the state quality policy coordinator in the Slovak Republic, SOSMT. The competition is governed by the statute as the principal program document and rules of the competition that set out the fundamental principles of the competition and the relationships between individual competitors and partners of the competition.

\section{Categories of the competition}

The Competition is designed for all organizations active in production or provision of services and for public administration organizations registered in the Slovak Republic according to valid legal regulations. Participation by both an organization and an organizational unit thereof is not permitted in the same year.

The candidates for the National Quality Award of the Slovak Republic are divided into the following categories (First Information on the Competition and the Application Form for the National Quality Award of the Slovak Republic 2012, 2011):

A) Large organizations producing products and providing services:

A1) Organizations producing products from 251 employees

A2) Organizations providing services from 51 employees

B) Small and medium-sized organizations producing products and providing services:

B1) Organizations producing products with up to 250 employees

B2) Organizations providing services with up to 50 employees

C) Public sector organizations (irrespective of the size):

C1) State administration organizations

C2) Self-governing region organizations

C3) Other public sector organizations 


\section{Levels of the award}

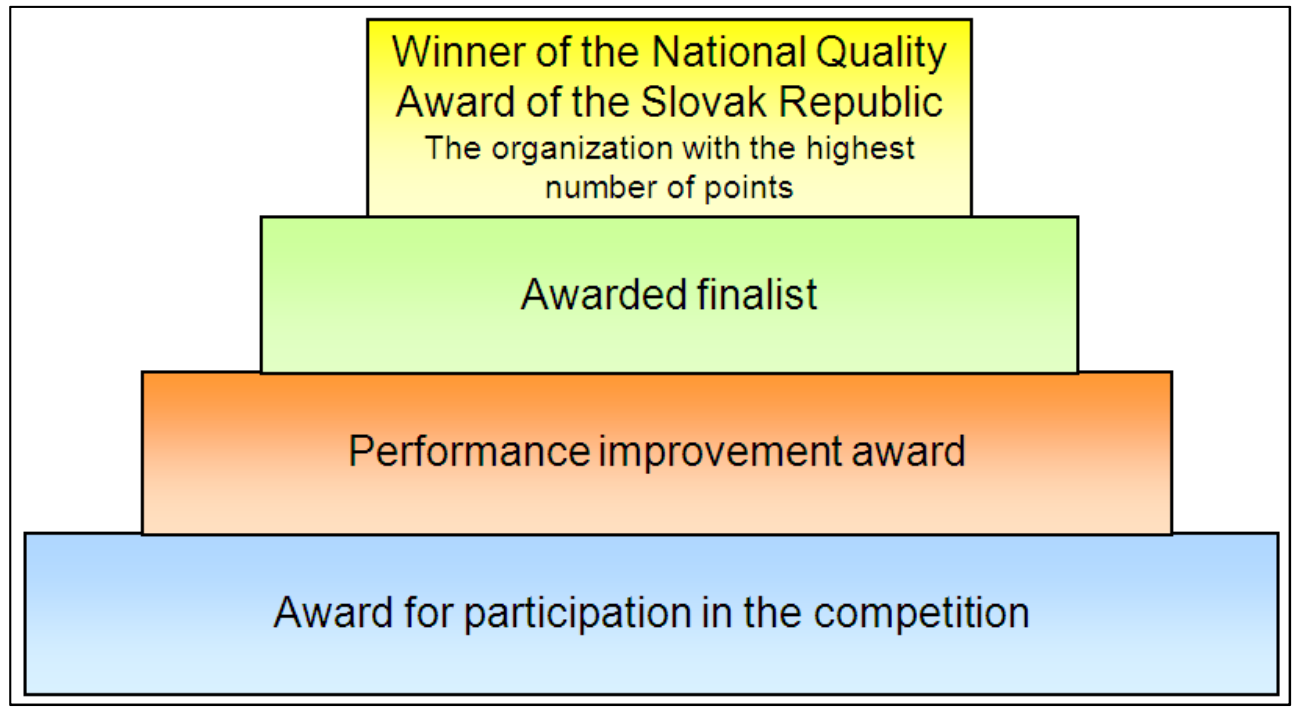

Fig. 1 Levels of the National Quality Award of the Slovak Republic

\section{EFQM Excellence Model (maximum of 1,000 scores)}

- Winner of the National Quality Award of the Slovak Republic (the organization with the highest number of points)

- Awarded Finalist (401 and more points)

- Performance Improvement Award (301 - 400 points)

- Award for Participation in the Competition (200 - 300 points)

\section{CAF Model (maximum of 900 scores)}

- Winner of the National Quality Award of the Slovak Republic (the organization with the highest number of points)

- Awarded Finalist (361 and more points)

- Performance Improvement Award (271 - 360 points)

- Award for Participation in the Competition (180 - 270 points)

\section{METHODOLOGY}

The competition National Quality Award of the Slovak Republic is annually organised by SOSMT who is at the same time a coordinator of the National Quality Programme of the Slovak Republic for years of 2009 - 2012. It is a task of SOSMT to evaluate last four years of the National Quality Programme and its main activities. Therefore all organisations of the public and private sector that were awarded in $2000-2012$, have been approached by SOSMT with the questionnaire "Participation in the National Quality Award of the Slovak Republic and its benefits." 65 organisations have been approached all together 
and 35 out of them filled out the questionnaire, that means $53.8 \%$ response rate. The questionnaire was anonymous and its main aim was to get participants' view and opinion on different stages of the competition, support offered by SOSMT and ways of promotion in order to improve it for following years. At the same time SOSMT wanted to analyse expectations, benefits and success achieved by participants in the course of the competition or during implementation of recommendations and improvements provided.

The questionnaire contains fifteen questions (Table 1).

\section{Table 1 - Questionaire "Participation in the National Quality Award of the Slovak Republic and its benefits”.}

\begin{tabular}{|l|}
\hline 1. How did you become aware of the competition? \\
\hline SOSMT website \\
\hline SOSMT newsletter \\
\hline Information e-mail from Quality department \\
\hline First information on the competition \\
\hline Press \\
\hline TV \\
\hline Other organisation's recommendation \\
\hline Other \\
\hline From colleagues. \\
\hline Information on the trainings. \\
\hline Slovak Quality Company. \\
\hline Previous participation in the competition. \\
\hline Magazine "Kvalita". \\
\hline 2. How many times had your organisation participated the competition? \\
\hline 1x \\
\hline 2x \\
\hline More times \\
\hline 1x, but we did not finish an annual round \\
\hline 3. What expectation did you enter the competition with? (multiple answers possible) \\
\hline Prestigious award obtaining \\
\hline Increasing competitiveness of your organisation \\
\hline Increasing awareness on your organisation \\
\hline More efficient functioning of the organisation and initiation of continuous improvement \\
\hline Benchmarking \\
\hline Detection of weaknesses \\
\hline Other \\
\hline Possibility of contact and consultancy with TQM experts. \\
\hline 4. Were your expectations met? \\
\hline Yes \\
\hline No \\
\hline Partially \\
\hline I can not take measure \\
\hline Other \\
\hline $\mathbf{5 .}$ How would you describe a benefit for your organisation from participation in the \\
competition? (multiple answers possible) \\
\hline $\mathbf{5}$ a)Human resources \\
\hline Decreasing staff turnover \\
\hline
\end{tabular}


Increasing number of registered improvement and innovation proposals from employees

Decreasing number of registered employees complaints

Internal communication improvement

Increasing employees satisfaction with working conditions

Increasing employees satisfaction with management, interpersonal reliationships at workplace, communication

Other

Negative employees approach to quality providing.

Process improving (HR, adaptation process, more efficient recruitment).

Benefit is unmeasurable.

Outputs were general.

\section{5 b) Customer/Citizen}

Increasing customer satisfaction with product/service qualiy

Decreasing number of claims/complaints

Acquirement of new customers

Increasing number of orders/contracts/submission

Faster solving of claims/complaints

Organisation image/good name improvement

Improved communication with customers

Other

Internet service support improving.

Clarifying the name "customer", "stakeholders".

Outputs were general.

5 c) Performance/Resources

Increasing permanent income

Increasing market share

Shortening the processing and delivery time of the product/service

Decreasing administrative burden

Decreasing environmental burden

Increasing number of obtained projects/orders

Decreasing operating costs

Increasing savings thanks to rationalisation actions

Decreasing amount of outstanding claims

Decreasing rate of loan encumbrance

Increasing number of partners

Increasing labour productivity

Other

Benefit in this area is unmeasurable.

More efficient and clarified office activities.

Outputs were general.

Action plan for 2011 - 2015 creating.

6. Did you take part a training on quality model during the competition?

Yes

No

I do not know

7. How do you evaluate trainings on quality models?

Very satisfied

Satisfied

Dissatisfied

I do not know, I do not remember

8. How do you evaluate a support from the competition announcer and organiser? 


\section{Very satisfied}

Satisfied

Dissatisfied

I do not know, I do not remember

9. Did you use an external consultant during the competition?

Yes

No

10. Did you carry out any actions suggested to you by trainers?

Yes, all of them

Yes, but only some of them

No

I do not know

11. Do you continue in the implementation of the quality model you have participated in the competition?

Yes

No

No, we implement different quality model

12. What tool or quality model was implemented in your organisation before your participation in the competition?

ISO 9000

ISO 14000

Another ISO standard

Balanced Scorecard

The EFQM Excellence Model

The CAF Model

SIX SIGMA

Other

STN EN ISO/IEC 17025

CAF or ISO 9000 in some parts of organisation.

OHSAS: 18001

AMPS

13. Was any type of audit carried out in your organisation in 2009-2012 (personal, process, financial, customer etc.)?

Yes

No

14. Do your organisation plan to participate the competition again?

Yes, next year

Yes, we consider this opportunity

I do not know

No

15. Would you recommend a participation in the competition to other organisation? Yes

No

I do not know 


\section{SURVEY RESULTS AND INTERPRETATION}

\section{1) How did you become aware of the competition? (Fig. 2)}

The Quality Department of SOSMT addresses public administration organisations and organisations of the private sector and offers them a possibility to participate in the competition using different communication tools each year, e.g. web page, direct information e-mails, newsletter, bulletins and so on. 35\% of respondents quote that they got the information about the competition from the direct information email that was sent by the Quality Department. 11\% of organisation decided to participate in the competition due to the printed version of the bulletin " 1 st competition information" distributed by the Quality Department. Other significant communication means in relation to the competition and its potential participants are the SOSMT web page and recommendation of previous participants.

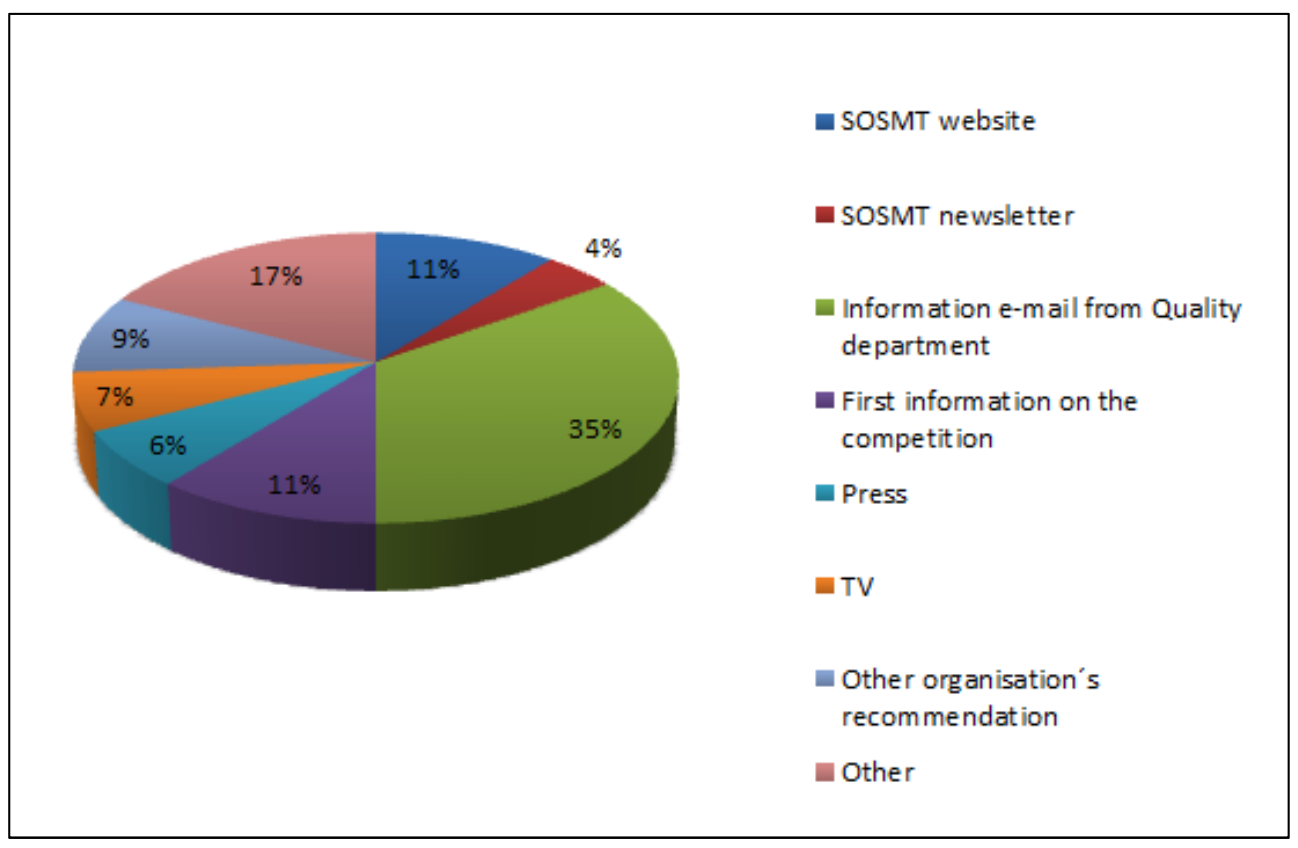

Fig. 2 Results of question 1: How did you become aware of the competition?

\section{2) How many times had your organisation participated the competition?} (Fig. 3)

Most of the organisations that took part in the competition in the past, were participants of just one competition annual round (62\%), 29\% of organisations participated in the competition twice and $9 \%$ of them more than twice. This fact is in line with the aim of the SOSMT to motivate previous participants to backtrack after three years to the competition after becoming a winner and assess own improvement based on the external assessors recommendations again. 


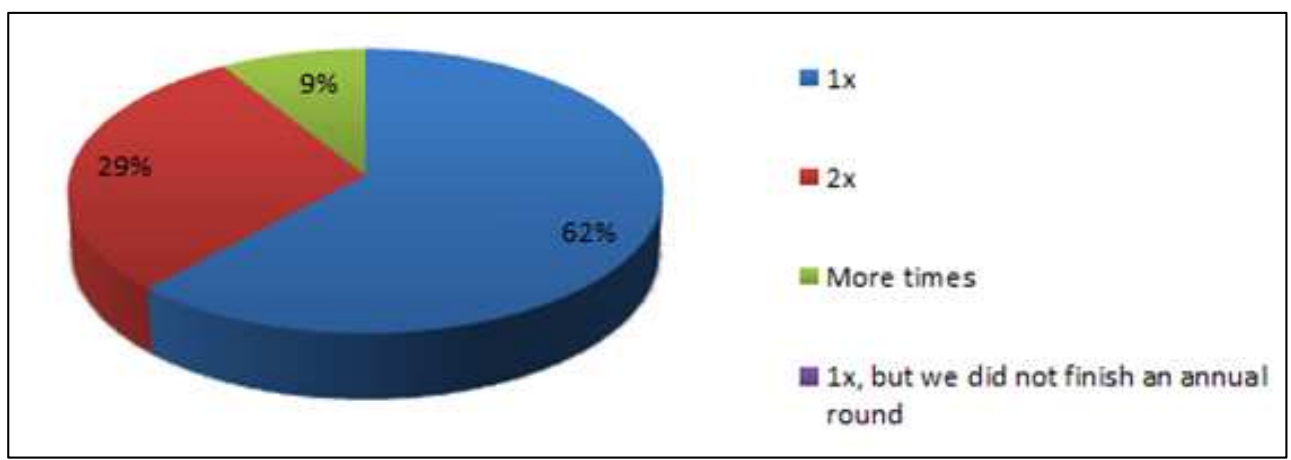

Fig. 3 Results of question 2: How many times had your organisation participated the competition?

\section{3) What expectation did you enter the competition with? (Fig. 4)}

Organisations entered the competition with different expectations. $20 \%$ of them expected raise of their performance effectiveness and the beginning of the continuous improvement, $21 \%$ of organisations aimed at uncovering their weaknesses and $17 \%$ of the rest wanted to raise awareness about their own organisation. $15 \%$ of respondents aimed at gaining a prestige appreciation and benchmark with other organisations. Other reasons of the organisation participations were enhancing of competitiveness and possibility of consultancy with experienced Total Quality Management professionals.

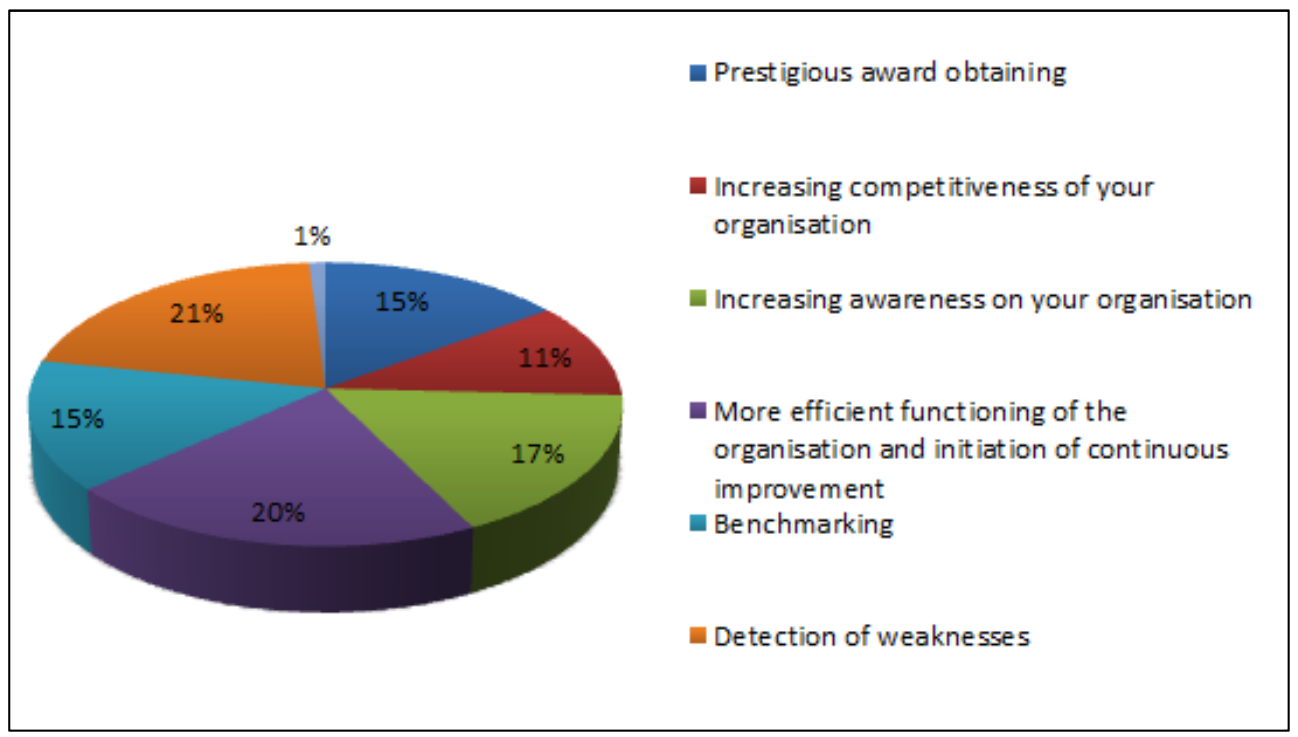

Fig. 4 Results of question 3: What expectation did you enter the competition with? 


\section{4) Were your expectations met?}

More than a half of organisations mentioned that their expectations were met and the rest confirmed their expectations were met partially.

\section{5) How would you describe a benefit for your organisation from participation in the competition?}
a) Impact of participation in NQASR on human resources (Fig. 5)

The participation in the competition brings to organisations positive results in different areas, as e.g. human resources, relations with customers and overall performance.

$52 \%$ of respondents stated that the most significant benefit in the human resources area was an improvement of an internal communication. The increase of the employees' satisfaction with the organisation management and working conditions, relationships at workplace and communication, increase of the proposals submitted by employees (resulting in the lower staff turnover) were also mentioned.

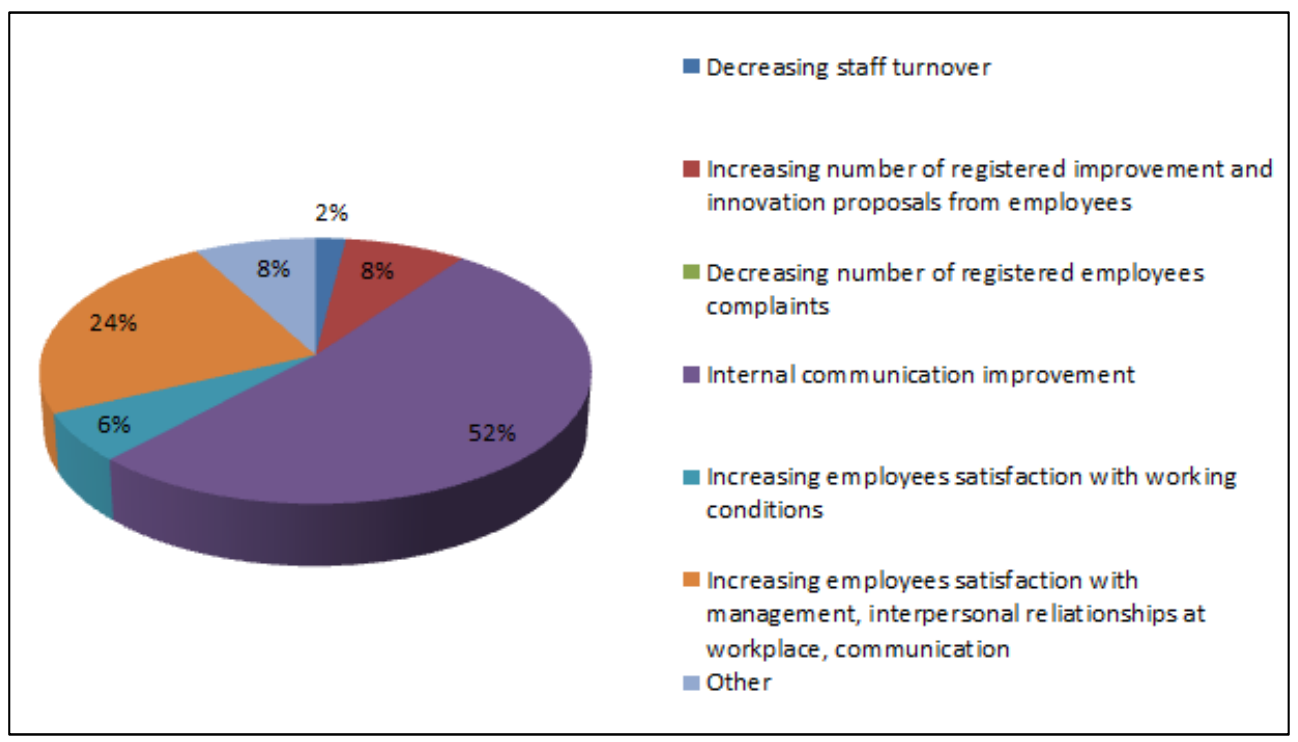

Fig. 5 Results of question 5 a) Impact of participation in NQASR on human resources

\section{b) Impact of participation in NQASR on customer/citizen (Fig. 6)}

From the point of impact on the customer, $44 \%$ of respondents confirm that their participation in the competition has brought along the image and goodwill improvement. The improvement of customer communication, increase of customer satisfaction with product/service quality, new customers acquiring as 
well as to cut down the number of appeals and complaints were also mentioned by respondents as other benefits.

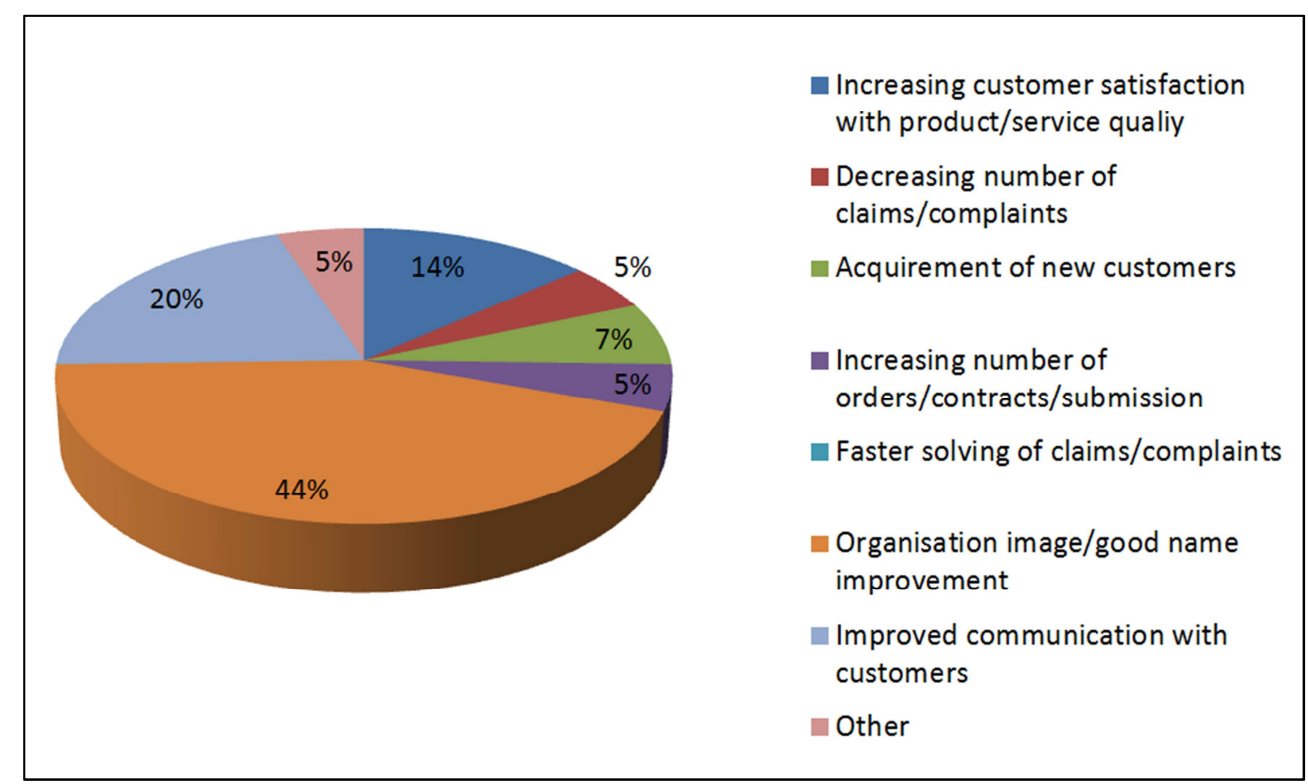

Fig. 6 Results of question 5 b) Impact of participation in NQASR on customer/citizen

\section{c) Impact of participation in NQASR on performance/resources} (Fig. 7)

The participation in the competition has a positive benefit also in the area of organisations' performance and resources. $22 \%$ of organisations claim their participation had an impact on their productivity enhancement, $17 \%$ of them consider lowering of operation costs as a positive thing, $14 \%$ of respondents can air themselves with acquiring of new partners. 


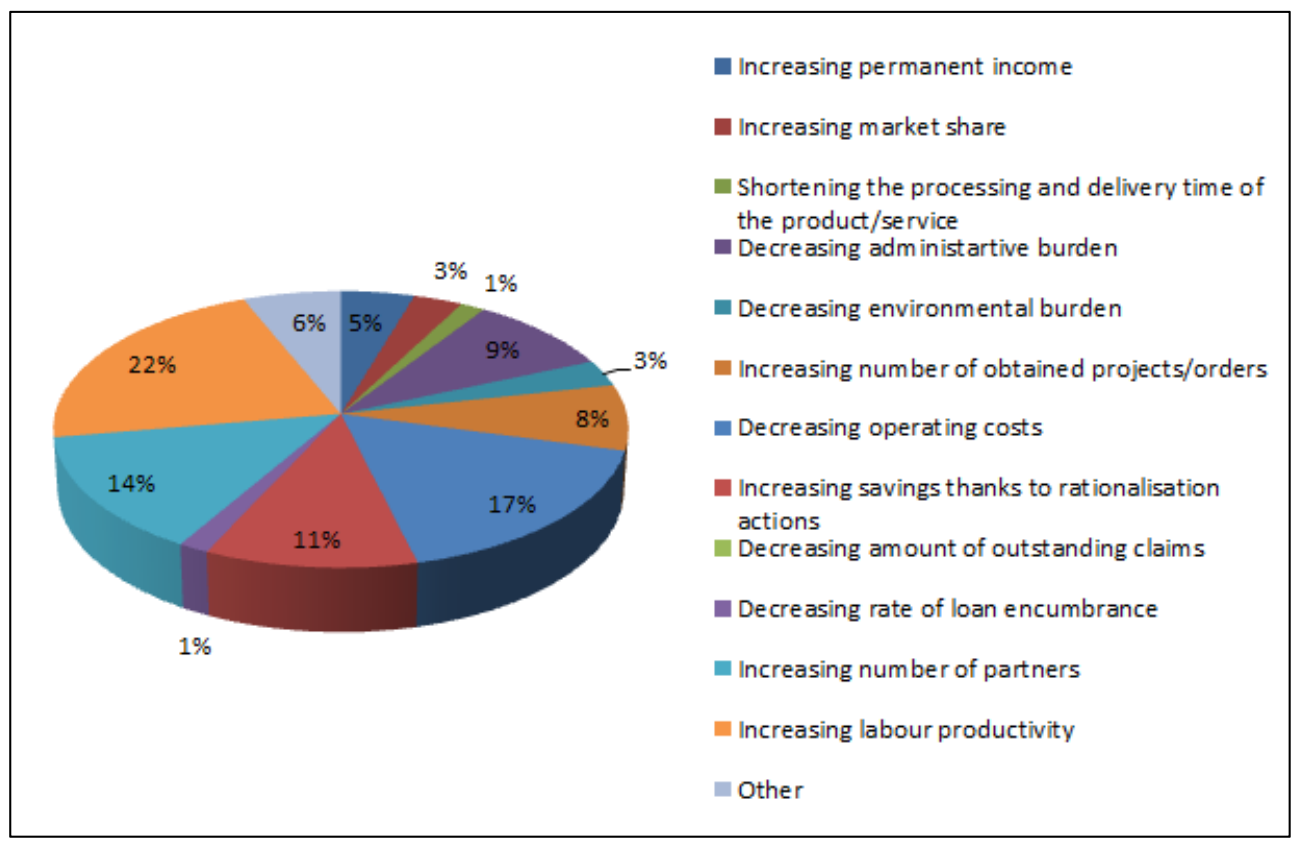

Fig. 7 Results of question 5 c) Impact of participation in NQASR on performance/resources

The Quality Department of SOSMT organises regularly trainings on the EFQM Excellence Model and CAF Model free of charge. These trainings are offered not only to all organisations participating in the competition but also to public and private organisations that area interested in quality models. These trainings focus on the definition and understanding of the models as well as scoring. The part of these trainings there are also workshops that offer participants also practical experience with quality models. Competition participants can also attend the trainings on a self-assessment report preparation and individual consultations focusing directly on the given organisation. All trainings and consultancies that are free of charge are led by experienced quality management professionals with long-term practice with quality models who are able to offer valuable advice and recommendations to participants.

As already mentioned, trainings are offered to all organisations that run in to the competition.

Respondents were asked about the training the following related questions:

6) Did you take part a training on quality model during the competition?

7) How do you evaluate trainings on quality models?

The responses can be summarised as follow: 
- It is possible to allege that there is a great interest in trainings in general, 94\% of respondents attended training on quality models, self-assessment report preparation and following consultancies.

- $41 \%$ of respondents evaluated trainings they had attended as very satisfying, $53 \%$ of them evaluated trainings as satisfying and $6 \%$ of organisations marked trainings as unsatisfactory.

8) How do you evaluate a support from the competition announcer and organiser? (Fig. 8)

Apart from different trainings, SOSMT offers as an announcer and organiser of the competition also other supports to participants - consultancy, provides different educational and working documents that are used in the course of the competition. $43 \%$ of organisations were very satisfied with the mentioned support, $51 \%$ of them were satisfied. Only $3 \%$ of organisations consider the support offered by SOSMT as insufficient.

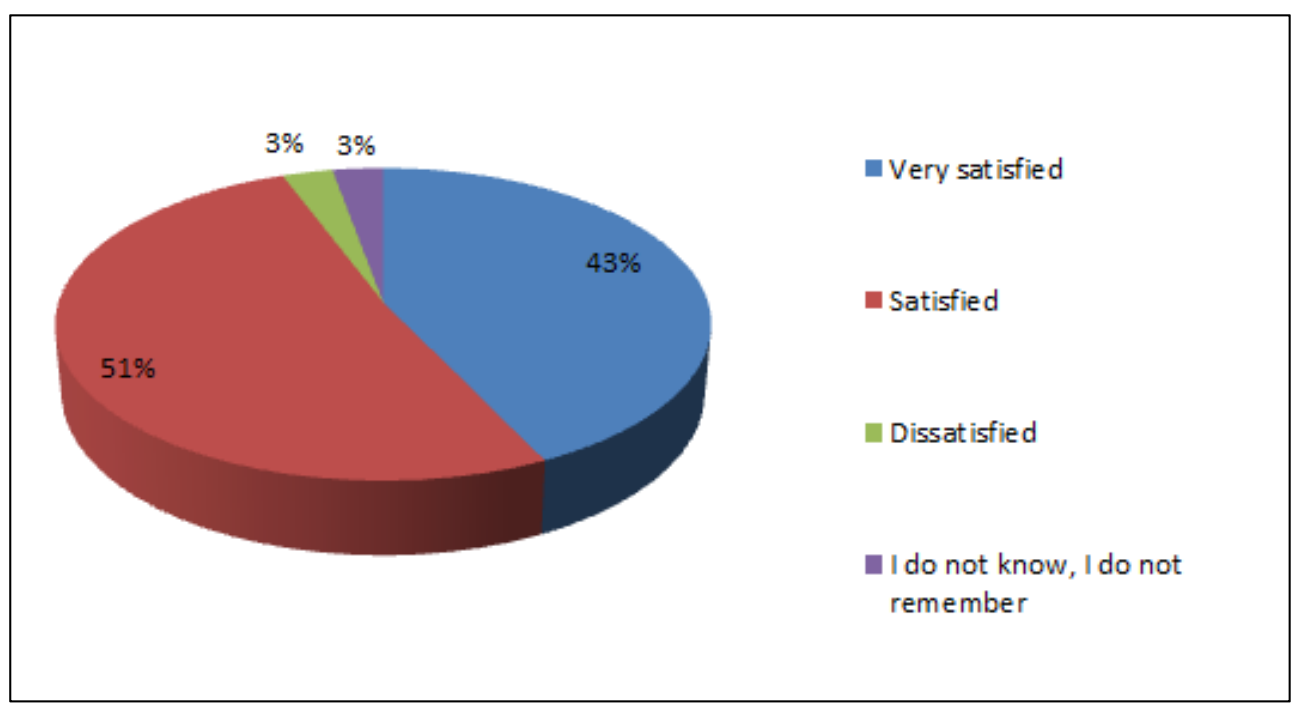

Fig. 8 Results of question 8: How do you evaluate a support from the competition announcer and organiser?

9) Did you use an external consultant during the competition?

Organisations have a possibility to contract own external consultant. The survey showed that $41 \%$ of respondents did so and used a help of an external person.

10) Did you carry out any actions suggested to you by trainers? (Fig. 9)

External assessors have a duty to support competition participants in the quality models scope and guide them on the right journey through the implementation. As a part of site visits, proposal of different improvements that might help the 
organisations overcome barriers and remove weaknesses in the course of the quality model implementation are suggested. All measures suggested by external assessors were realised by $37 \%$ of organizations, $57 \%$ organizations selected and implemented only some of them.

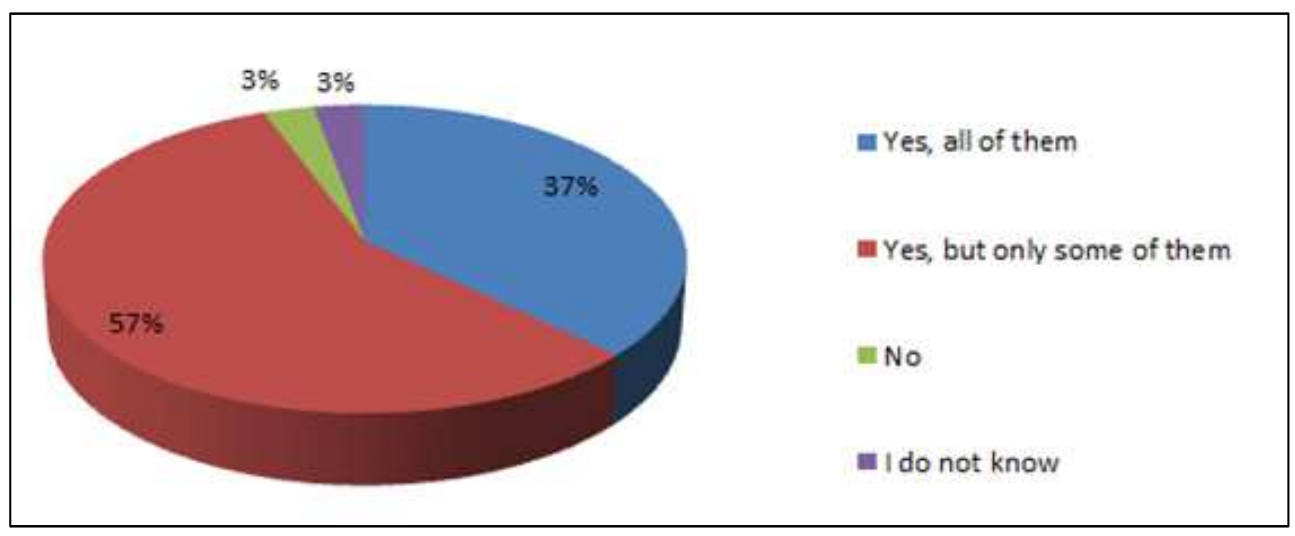

Fig. 9 Results of question 10: Did you carry out any actions suggested to you by trainers?

\section{1) Do you continue in the implementation of the quality model you have participated in the competition? (Fig. 10)}

Most of organisation (69\%) that took part in the competition according to the EFQM Excellence or CAF Model, follow the implementation thenceforth. $20 \%$ of organisations implement a different quality model.

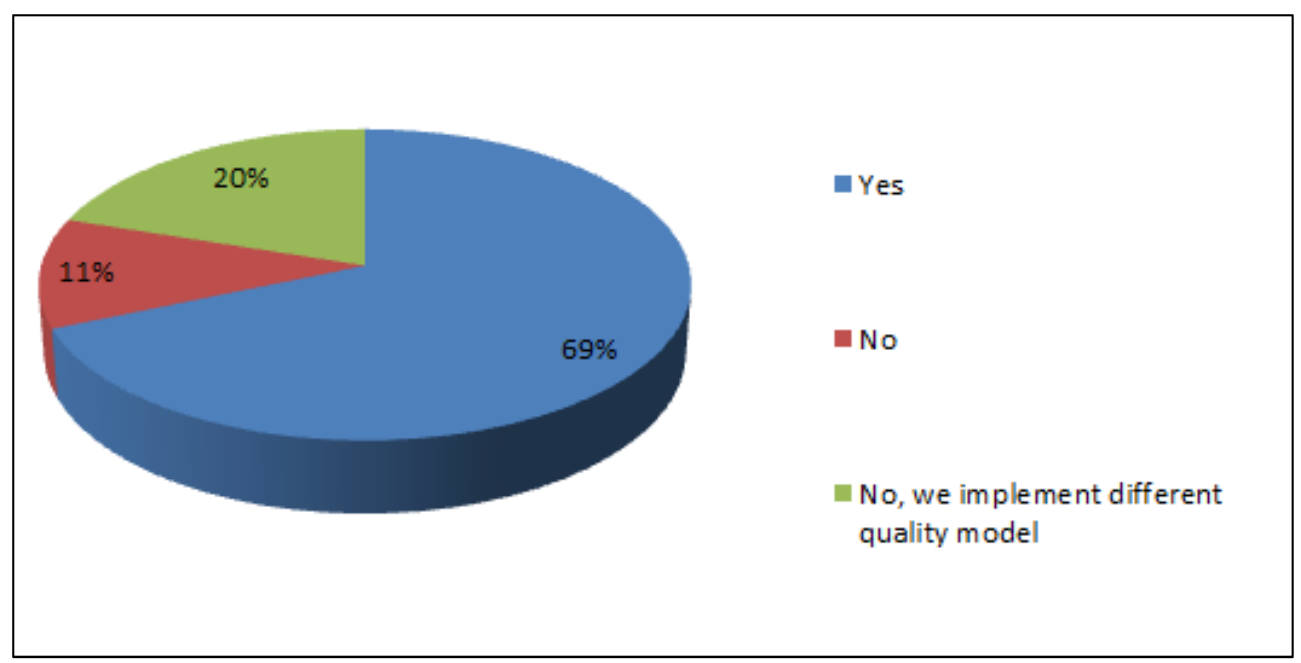

Fig. 10 Results of question 11: Do you continue in the implementation of the quality model you have participated in the competition? 
12) What tool or quality model was implemented in your organisation before your participation in the competition? (Fig. 11)

Almost each organisation, either of the public or private sector that entered the competition, had implemented some quality tool before. Most of them (39\%) implemented the ISO 9000 standard, 17\% of them had experience with ISO 14000 and other ISO standards. Other quality tools were represented by the EFQM Excellence model, CAF Model or SIX SIGMA.

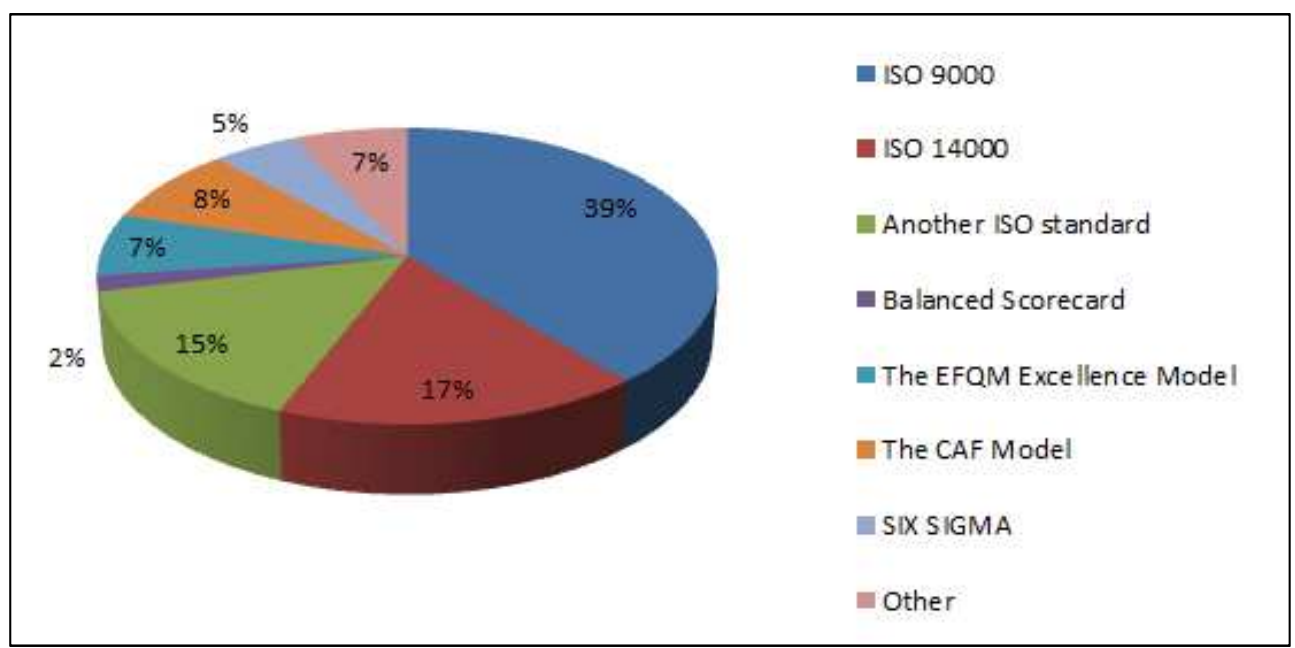

Fig. 11 Results of question 12: What tool or quality model was implemented in your organisation before your participation in the competition?

13) Was any type of audit carried out in your organisation in $2009-2012$ (personal, process, financial, customer etc.)?

Most organisations (71\%) were audited in the course of 2009 - 2012 (a specific type of audit - personal, process, financial, customer audit, etc.) and it resulted in the implementation of different improvement measures. The measures applied by organisations are mentioned below. The overview of accepted measures and improvements resulting from performed audits:

- increase of the work productivity,

- improve internal standards related to the financial management,

- internal measures to improve lab work,

- organisational changes and employee savings,

- food safety,

- measures for the continuous improvement of the quality management system recommended by auditors Increase amount of trainings,

- Peer Review WANO - improvement of safety and raise of the safety culture level,

- 2010 and 2011 - certification and surveillance audit - improvement of effectiveness and integration of the management system (ISO 9001; ISO 14001; ISO 18001), 
- action improvement plan - compliance with ISO 9000 standard and MAAE requirements,

- complex revision of the process map with respect to the increase of the process effectiveness,

- KPI analysis, PPI, internal communication.

14) Do your organisation plan to participate the competition again? (Fig. 12)

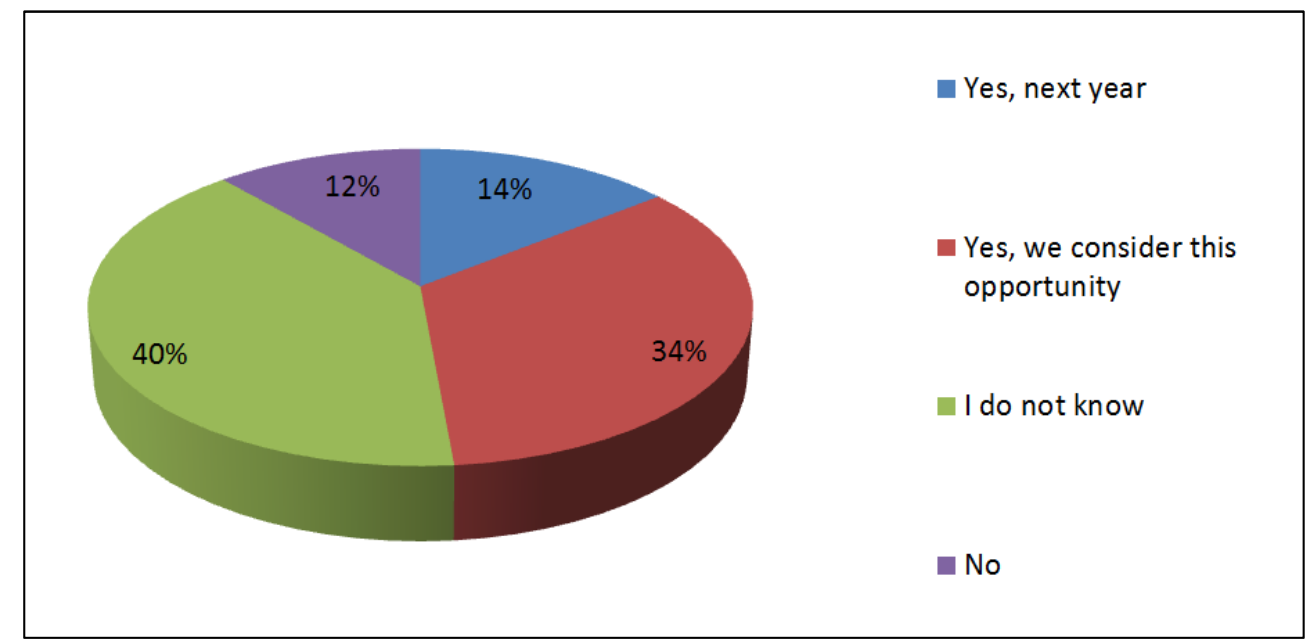

Fig. 12 Results of question 14: Do your organisation plan to participate the competition again?

\section{5) Would you recommend a participation in the competition to other organisation?}

Most of the organisations participating in the competition (88\%), would also recommend to other organisations to enter the competition.

\section{RECOMENDATIONS}

SOSMT also continuously improves its activities. Organisations were also asked to recommend SOSMT suggestions in order to raise the quality level of the following competition annual sets. Their recommendations are related to:

Support, promotion and media promotion:

- raise the level of promotion in media towards the public,

- promote awarded finalists in media and on the SOSMT web page during the whole year. 
The level of SOSMT support:

- to offer a possibility of more intensive communication and consultancy during the first self-assessment and self-assessment report preparation and during the whole competition,

- trainings should be differentiated according to the previously attended trainings in order to prevent from repeating topics that have been already attended by a part of stakeholders.

Added value of the participation in the competition:

- to intervene awarded organisations with a possibility of benchmarking with the best participants in model criteria they wish to improve,

- to suggest organisations concrete improvements they can immediately implement in their organisations,

- to raise effort of added value creation for competition participants.

Competency of trainers, consultants and assessors:

- trainers and consultant should be aware in more depth an organisational environment,

- increase competency, professionalism and knowledge of trainers,

- assessors should more motivate and support participants during site visit.

Time perspective:

- prolong the period necessary for the self-assessment report preparation,

- to organise trainings earlier and in more depth in order to minimize time stress.

Competition methodology:

- large organisations with over 1000 employees should have a possibility to train more than two employees.

As the questionnaire survey was participated by organisations present in the competition between $2000-2012$, it is necessary to mention that most of their recommendations have been already implemented during last years.

\section{CONCLUSIONS}

It is necessary to stress that not all organisations who have implemented and had a certified quality management system, are potential candidates for the competition participants. It is not enough to follow the success concept (Zgodavová, K., Slimák, I., 2011, p.1), organisations have to also prove their excellence in their performance.

SOSMT will focus on the most effective way of how to approach potential competition participants and that is to approach them with a direct email information. The importance of the competition promotion cannot be underestimated as well as promoting winners and finalist during the whole year. SOSMT will also continue in providing diversity of trainings and strengthen consultancies. 
Expectations of most organisations entering the competition have been met completely or partially. The quality model implementation and site visit based recommendations were main benefits of participating in the competition that resulted in success and added value in different areas of the organisation and its performance.

Organisations that have an experience of at least one year participation in the competition, claim its importance. It is also confirmed by the fact that organisations that became winners of its category in the past, backtrack to the competition after three and more years to benchmark their improvements and advancement. The competition is a strong tool that is able to assist an organisation on its journey to success and excellence.

\section{REFERENCES}

CAF Resource Center (2006), Common Assessment Framework, EIPA, Maastricht.

CAF Resource Center (2012), Common Assessment Framework, EIPA, Maastricht.

European Foundation for Quality Management (2010), The EFQM Excellence Model, EFQM, Brussels.

Slovak Office of Standards, Metrology and Testing, First Information on the Competition and the Application Form for the National Quality Award of the Slovak Republic 2012, Bratislava.

Zgodavová, K., Slimák, I. (2011): Focus on Success $\left(15^{\text {th }}\right.$ anniversary issue editorial), Quality Innovation Prosperity, Vol. 15, no. 1, 2011, pp. 1-4

\section{ABOUT THE AUTHOR}

Mgr. Monika Jurkovičová, MBA, Slovak Office of Standards, Metrology and Testing, Slovakia, e-mail: monika.jurkovicova@ normoff.gov.sk

Ing. Katarína Kašubová, Slovak Office of Standards, Metrology and Testing, Slovakia, e-mail: katarina.kasubova@normoff.gov.sk 